Tropical Journal of Pharmaceutical Research September 2020; 19 (9): 1815-1819

ISSN: $1596-5996$ (print); 1596-9827 (electronic)

(C) Pharmacotherapy Group, Faculty of Pharmacy, University of Benin, Benin City, 300001 Nigeria.

\title{
Echinacoside attenuates lipopolysaccharide-induced acute lung injury in newborn mice via inactivation of NF- KB/NLRP3 signaling pathway
}

\author{
Meijiao Fu, Tong Shen*, Ying Yang, Yaling Zheng, Lilin Zhong \\ Department of Pediatric Internal Medicine, Women and Children's Hospital, School of Medicine, Xiamen University, Xiamen \\ City, Fujian Province 361000, China
}

*For correspondence: Email: shentong20615@163.com; Tel: +86-592-2663952

Sent for review: 8 July 2020

Revised accepted: 28 August 2020

\begin{abstract}
Purpose: To investigate the effect of echinacoside (ECH) on acute lung injury (ALI) and the underlying mechanism of action.

Methods: The ALI model was established through intranasal instillation of lipopolysaccharide (LPS). Lung tissue damage was determined using hematoxylin and eosin (H\&E) staining and lung wet-to-dryweight ratio. Bronchoalveolar lavage fluid (BALF) protein concentration, cell count, and cytokine level were evaluated. Western blotting was used to determine protein expression level.

Results: $E C H$ attenuated lung tissue injury and lung wet-to-dry-weight ratio in the $A L I$ model $(p<0.01)$. The total protein content and number of total cells, neutrophils, and macrophages increased in BALF of mice treated with LPS, but these increases were reversed by $E C H$ treatment $(p<0.01)$. The levels of $T N F-\alpha$ and IL-1 $\beta$ increased in BALF and lung tissue of LPS-treated mice; however, ECH treatment decreased these changes $(p<0.01)$. In addition, $E C H$ inhibited the activation of the nuclear factor- $K B$ (NF-KB)/NLR family pyrin domain containing 3 (NLRP3) pathway in LPS-treated mice $(p<0.01)$. Conclusion: Echinacoside attenuates LPS-induced ALI via inactivation of the NF-KB/NLRP3 pathway, making echinacoside a potential drug for the treatment of ALI.
\end{abstract}

Keywords: Echinacoside, Acute lung injury, Lipopolysaccharide, Nuclear factor-KB, NLR family pyrin domain containing 3

\begin{abstract}
This is an Open Access article that uses a fund-ing model which does not charge readers or their institutions for access and distributed under the terms of the Creative Commons Attribution License (http://creativecommons.org/licenses/by/4.0) and the Budapest Open Access Initiative (http://www.budapestopenaccessinitiative.org/read), which permit unrestricted use, distribution, and reproduction in any medium, provided the original work is properly credited.

Tropical Journal of Pharmaceutical Research is indexed by Science Citation Index (SciSearch), Scopus, International Pharmaceutical Abstract, Chemical Abstracts, Embase, Index Copernicus, EBSCO, African Index Medicus, JournalSeek, Journal Citation Reports/Science Edition, Directory of Open Access Journals (DOAJ), African Journal Online, Bioline International, Open-J-Gate and Pharmacy Abstracts
\end{abstract}

\section{INTRODUCTION}

Pediatric pneumonia, caused by bacterial or viral infection, is common in infants and children, and is an important cause of mortality in children [1]. Studies show that pneumonia is the most common risk factor for acute lung injury (ALI) [2]. In clinical practice, infection-induced $A L I$ is a serious condition requiring intensive care.
Damage to alveolar epithelial integrity, hyaline membrane formation, increased permeability, activated inflammation response, pulmonary edema, hypoxemia, and atelectasis usually occur in ALI patients [3]. Therefore, infectioninduced $A L I$ is a serious threat to infants and children. At present, antiviral drugs and antibiotics are the major therapeutic strategies for ALI [4]. However, the serious side effects of 
chemical drugs and overuse of antibiotics limit the effectiveness of ALI therapy [1]. Therefore, it is essential to investigate new drugs that show promise for ALI therapy.

Cistanche deserticola is a widely used Chinese herbal medicine with many pharmacological properties, such as anti-inflammatory and antioxidant properties [5,6]. Recently, accumulating evidence revealed that echinacoside $(E C H)$, a phenylethanoid glycoside extracted from C. deserticola [7], exerts neuroprotective and anti-inflammatory effects in vivo and in vitro [7]. For example, $\mathrm{ECH}$ attenuated nerve injury and neuroinflammation in Parkinson's disease through modulating the p38MAPK and NF-kB pathways in [8]. Furthermore, ECH alleviated spinal cord injury by reducing activity of the NLRP3 pathway [9]. Moreover, the effects of $\mathrm{ECH}$ on $\mathrm{ALI}$ have been reported. Zhang et al demonstrated that $\mathrm{ECH}$ alleviated oleic acid-induced lung injury [10]. However, the role of $\mathrm{ECH}$ in the inflammatory response of $A L I$ is unclear.

Therefore, the aim of the study was to investigate the role of $\mathrm{ECH}$ in $\mathrm{ALI}$ and its inflammatory response and study the underlying mechanism in these processes.

\section{EXPERIMENTAL}

\section{Animals and experimental design}

Twenty-four neonatal C57BL/6 mice were obtained from Beijing Vital River Laboratory Animal Technology (Beijing, China). The mice were divided into four groups: control, lipopolysaccharide (LPS), LPS + ECH (10 $\mathrm{mg} / \mathrm{kg})$, and LPS + ECH (30 mg/kg). To induce lung injury, $50 \mu \mathrm{L}$ of LPS (2 mg/kg) (Sigma, St. Louis, MO, USA) was instilled intranasally in mice. In the LPS + ECH $(10 \mathrm{mg} / \mathrm{kg})$ and $\mathrm{LPS}+\mathrm{ECH}(30 \mathrm{mg} / \mathrm{kg})$ groups, the mice also received $10 \mathrm{mg} / \mathrm{kg} \mathrm{ECH}$ and $30 \mathrm{mg} / \mathrm{kg} \mathrm{ECH}$, respectively, after the LPS challenge. All animal experiments were conducted in accordance with the National Institutes of Health Laboratory Animal Care and Use Guidelines [11]. The protocols of all animal experiments were approved by the Ethics Committee of Women and Children's Hospital, School of Medicine, Xiamen University (approval no. 2020-011).

\section{Hematoxylin and eosin (H\&E) staining}

After receiving the indicated treatments, mice were euthanized and lungs were collected. The middle lobe of the right lung was reserved to determine lung wet-to-dry-weight ratio (W/D).
The remainder of the lung tissue was cut into blocks of approximately $4 \mathrm{~mm}^{3}$, fixed in paraformaldehyde, embedded in paraffin, and 5$\mu \mathrm{m}$ sections were prepared. Sections were deparaffinized, rehydrated, stained with $\mathrm{H} \& \mathrm{E}$, and viewed under a light microscope (Olympus, Tokyo, Japan).

\section{Determination of lung W/D}

The middle lobe of the right lung was collected to determine lung wet weight. After the lung was dried for $48 \mathrm{~h}$ at $80^{\circ} \mathrm{C}$, the dry weight was recorded.

\section{Determination of cell number and protein expression in bronchoalveolar lavage fluid (BALF)}

BALF samples were collected and centrifuged, and cell pellets were lysed with red blood cell lysis buffer and resuspended in phosphatebuffered saline (PBS). Numbers of total cells, neutrophils, and macrophages were determined using a hemocytometer. Total protein content in BALF samples was determined using a bicinchoninic acid (BCA) kit (Sigma).

\section{ELISA}

BALF and lung tissues of mice were collected to determine the production of tumor necrosis factor-alpha (TNF- $\alpha$ ) and interleukin-1 $\beta$ (IL-1 $\beta$ ). The levels of TNF- $\alpha$ and IL-1 $\beta$ were determined using ELISA kits (R\&D Systems, Minneapolis, $\mathrm{MN}$ ) according to the manufacturer's protocols.

\section{Western blotting}

Lung tissues were lysed using RIPA buffer (Sigma). Proteins were quantified using the BCA method. Proteins in the lysates $(40 \mu \mathrm{g})$ were separated on SDS-PAGE gels. The separated proteins were transferred to PVDF membranes, and membranes were blocked by incubation with $5 \%$ skim milk for $1 \mathrm{~h}$. The PVDF membranes were probed with primary antibodies anti-p-p65 (1/1000), anti-p65 (1/1000), anti-NLR family pyrin domain containing 3 (NLRP3) (1/1000) and anti$\beta$-actin (1/2000) (Abcam, Cambridge, UK) at $4^{\circ} \mathrm{C}$ for $12 \mathrm{~h}$. Membranes were washed with PBS and then incubated with horse radish peroxidase (HRP)-conjugated anti-lgG secondary antibody (Abcam). $\beta$-actin was used as the control protein. The bands were visualized using the ECL detection kit (Thermo Fisher Scientific, Waltham, MA, USA). The band density analyzed using ImageJ software (National Institutes of Health, Bethesda, MD, USA. 


\section{Statistical analysis}

SPSS version 22.0 (Chicago, IL, USA) was used to analyze the data. All data are shown as mean \pm standard deviation (SD). Differences among groups were compared using one-way ANOVA with LSD post-hoc test. $P<0.05$ was considered statistically significant.

\section{RESULTS}

\section{ECH alleviates LPS-induced ALI}

The LPS-treated mice presented with marked lung damage characterized by lung tissue congestion and alveolar collapse, whereas $\mathrm{ECH}$ attenuated these changes (Figure 1A). Further, the W/D ratio of lung tissue in LPS-treated mice was significantly increased, but was decreased by treatment with $10 \mathrm{mg} / \mathrm{kg}$ and $30 \mathrm{mg} / \mathrm{kg} \mathrm{ECH}$ $(p<0.01$, Figure 1B). These results show that ECH alleviates LPS-induced ALI.
A

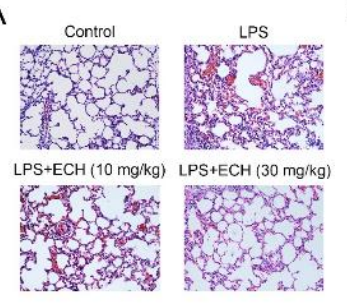

B

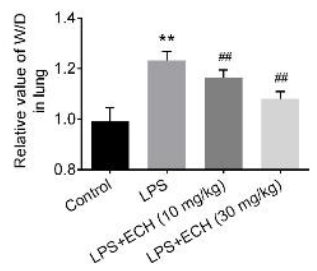

Figure 1: Effect of ECH on LPS-induced ALI. A. Effect of $\mathrm{ECH}$ (10 and $30 \mathrm{mg} / \mathrm{kg}$ ) on lung tissue injury was determined using H\&E staining of lungs of LPSinduced ALI mice. B. Effect of ECH (10 and $30 \mathrm{mg} / \mathrm{kg}$ ) on wet-to-dry weight ratio (W/D) of lung tissue was determined in LPS-induced ALI mice; ${ }^{* *} p<0.01$, compared to control group; \#\#< $<0.01$, compared to LPS group

\section{$\mathrm{ECH}$ alleviates LPS-induced inflammatory response}

The total protein content of BALF was increased in LPS-treated mice, but ECH decreased the total protein content $(p<0.01$; Figure 2A). Further, the number of total cells in BALF was increased in LPS-treated mice $(p<0.01$; Figure $2 \mathrm{~B})$. However, ECH decreased the number of total cells in BALF induced by LPS $(p<0.01$, Figure 2B). Similarly, the numbers of neutrophils and macrophages in BALF were significantly increased in LPS-treated mice, and this effect was reversed by $\mathrm{ECH}(p<0.01$, Figure $2 \mathrm{C}$ and $D)$. These results indicate the protective role of $\mathrm{ECH}$ against LPS-induced inflammatory response.

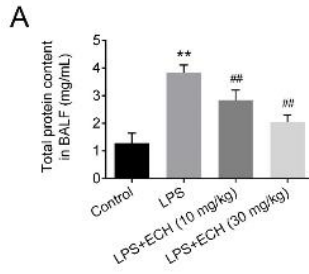

B

C

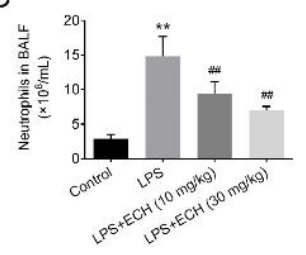

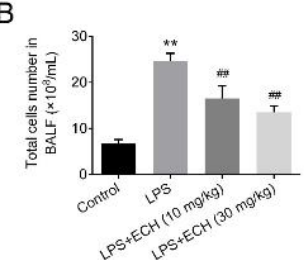

D

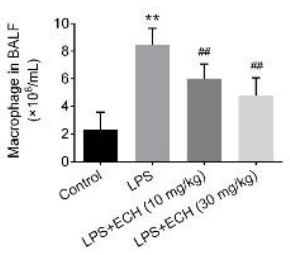

Figure 2: Effect of ECH on LPS-induced inflammatory response. The total protein content (A), total cell number $(B)$, number of neutrophils $(C)$, and number of macrophages (D) in bronchoalveolar lavage fluid (BALF) of mice treated with LPS and ECH (10 and 30 $\mathrm{mg} / \mathrm{kg}$, respectively); ${ }^{* *} p<0.01$, compared to control group. \#p< 0.01, compared to LPS group

\section{$\mathrm{ECH}$ alleviates LPS-induced cytokine production}

Production of TNF- $\alpha$ and IL-1 $\beta$ were elevated in BALF of LPS-treated mice (all, $p<0.01$, Figures $3 \mathrm{~A}$ and $3 \mathrm{~B}$ ). However, $\mathrm{ECH}$ reversed these changes $(p<0.01$, Figures $3 A$ and 3B). Similarly, TNF- $\alpha$ and IL-1 $\beta$ were elevated in lung tissue of LPS-treated mice, and these values were decreased by $\mathrm{ECH}(p<0.01$, Figure $3 \mathrm{C}$ and $\mathrm{D})$. Thus, ECH alleviates LPS-induced cytokine production.

A

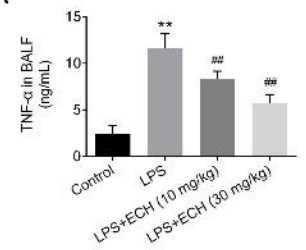

C

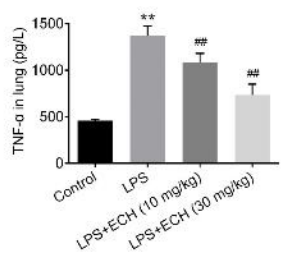

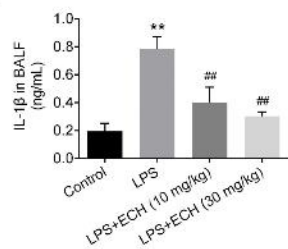

D

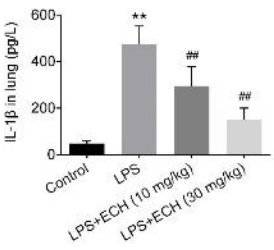

Figure 3: Effect of ECH on LPS-induced cytokine production. Levels of TNF- $\alpha$ (A) and IL-1 $\beta$ (B) in BALF of mice treated with LPS and ECH (10 and $30 \mathrm{mg} / \mathrm{kg}$ ). Levels of TNF- $\alpha$ (C) and IL-1 $\beta$ (D) in lung tissue of mice treated with LPS and $\mathrm{ECH}(10$ and $30 \mathrm{mg} / \mathrm{kg}$ ) were determined by ELISA; ${ }^{* *} p<0.01$, compared to control group, \#\#p<0.01, compared to LPS group 

ECH alleviates LPS-induced NF-KB/NLRP3
pathway activity

Phosphorylation of p65 to form p-p65, and NLRP3 expression in LPS-treated mice were increased $(p<0.01$, Figure 4). ECH decreased both p65 phosphorylation and NLRP3 expression $(p<0.01$, Figure 4). Thus, ECH inhibits activation of the NF-KB/NLRP3 pathway in LPSinduced ALI.

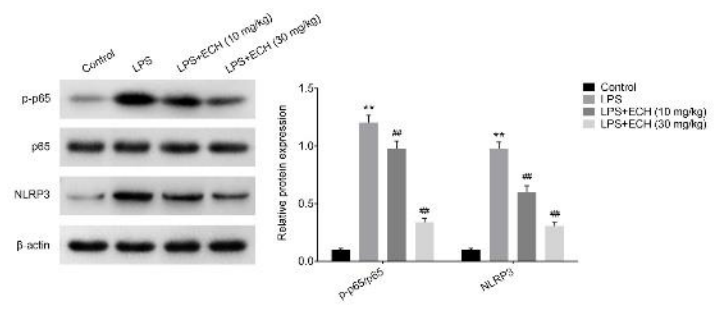

Figure 4: Effect of ECH on NF-kB/NLRP3 pathway in LPS-induced ALI. Western blotting was used to determine the levels of p-p65, p65, and NLRP3 in mice treated with LPS and $\mathrm{ECH}(10$ and $30 \mathrm{mg} / \mathrm{kg}$ ); ${ }^{* *} p<0.01$ compared to control group; \#\#p < 0.01 compared to LPS group

\section{DISCUSSION}

Pediatric pneumonia is a common disease in infants and children, and it is a major risk factor for ALI $[1,2]$. ALI induced by bacterial or viral infection is a serious condition with severe lung damage. Therefore, it is essential to identify effective therapeutic strategies for ALI. In this study, the effect of ECH on ALI was investigated, and results demonstrated that $\mathrm{ECH}$ attenuated LPS-induced ALI in newborn mice through inhibiting activation of NF-KB/NLRP3 signaling.

To determine the effect of $\mathrm{ECH}$ on infectioninduced ALI, LPS was used to establish the ALI model. In the LPS-treated mice, obvious lung damage with lung tissue congestion, alveolar collapse, and increased W/D ratio were observed, and were reversed by $\mathrm{ECH}$ administration. These results are in accordance with the study performed by Zhang et al [10], who found that $\mathrm{ECH}$ attenuated ALI induced by oleic acid in rats [10]. Thus, the results of this study indicate that $\mathrm{ECH}$ exerted a protective role in LPS-induced ALI.

In LPS-induced ALI, the inflammatory response has a critical role, and the excessive activation of neutrophils and macrophages aggravated ALI [12]. The previous study revealed that neutrophils could be recruited to the lungs and cause endothelial injury, thereby inducing lung edema during ALI [13]. Macrophages regulate the production of proinflammatory mediators in different pathological stages of ALI [14]. In this study, neutrophils and macrophages in BALF were increased in LPS-treated mice, and $\mathrm{ECH}$ decreased these changes. Further, the total protein content and total cell number in BALF were increased, and $\mathrm{ECH}$ also decreased these changes. In addition to immune cells, cytokines participate in ALI [13]. In this study, TNF- $\alpha$ and IL-1 $\beta$ were increased in BALF and lung tissue of mice treated with LPS, and ECH decreased these changes. Therefore, these results reveal that $\mathrm{ECH}$ alleviated LPS-induced inflammatory response and cytokine production.

NF-KB and NLRP3 signaling are important inflammatory signaling pathways and participate in regulation of ALI [15]. The level of NF-KB activation determines the severity of ALI [15]. Liu et al showed that NLRP3 was essential for paraquat-induced ALI [16]. Accumulating evidence has revealed that inactivation of the NF-KB and NLRP3 pathways reduced ALI $[17,18]$. In this study, the level of p65 phosphorylation and NLRP3 expression increased in mice treated with LPS, and $\mathrm{ECH}$ decreased these changes. In other words, $\mathrm{ECH}$ reversed LPS-induced changes in the NF$\mathrm{KB} / \mathrm{NLRP3}$ pathway. The influence of $\mathrm{ECH}$ on the NF-KB/NLRP3 pathway was in agreement with previous studies $[8,9]$. Zhang et al revealed that $\mathrm{ECH}$ protected against neuroinflammation via modulation of the NF-KB pathway in Parkinson's disease [8]. Gao et al showed that $\mathrm{ECH}$ alleviated spinal cord injury through suppression of the NLRP3 signaling pathway [9]. Taken together, these findings suggest that $\mathrm{ECH}$ may attenuate LPS-induced ALI through inactivation of the NF-KB/NLRP3 signaling pathway.

\section{CONCLUSION}

Echinacoside attenuates LPS-induced ALI via inactivation of the NF-KB/NLRP3 pathway. Thus, echinacoside is a promising drug for ALI therapy.

\section{DECLARATIONS}

\section{Conflict of interest}

No conflict of interest is associated with this work.

\section{Contribution of authors}

We declare that this work was done by the authors named in this article and all liabilities pertaining to claims relating to the content of this article will be borne by the authors. Meijiao Fu and Tong Shen designed the study, supervised data collection, and analyzed the data. Ying 
Yang interpreted the data and prepared the manuscript for publication. Yaling Zheng and Lilin Zhong supervised data collection, analyzed the data, and reviewed the draft of the manuscript. All authors read and approved the manuscript.

\section{Open Access}

This is an Open Access article that uses a funding model which does not charge readers or their institutions for access and distributed under the terms of the Creative Commons Attribution License (http://creativecommons.org/licenses/by/ 4.0) and the Budapest Open Access Initiative (http://www.budapestopenaccessinitiative.org/rea d), which permit unrestricted use, distribution, and reproduction in any medium, provided the original work is properly credited.

\section{REFERENCES}

1. Bai $D$, Han A, Cong S. The effect of down-regulation of CCL5 on lipopolysaccharide-induced WI-38 fibroblast injury: a potential role for infantile pneumonia. Iran $J$ Basic Med Sci 2018; 21(5): 449.

2. Kojicic M, Li G, Hanson AC, Lee K-M, Thakur L, Vedre J, Ahmed A, Baddour LM, Ryu JH, Gajic O. Risk factors for the development of acute lung injury in patients with infectious pneumonia. Crit Care 2012; 16(2): R46.

3. Cheifetz IM. Year in review 2015: pediatric ARDS. Resp Care 2016; 61(7): 980-985.

4. Hu H, Cao L. Treatment of pediatric pneumonia. J Applie Clin Pediatr 2011; 4: 3.

5. Kyung J, Kim D, Park D, Yang Y-H, Choi E-K, Lee S-P, Kim $T$-S, Lee Y-B, Kim Y-B. Synergistic antiinflammatory effects of Laminaria japonica fucoidan and Cistanche tubulosa extract. Lab Anim Res 2012; 28(2): 91-97.

6. Xiang Z, Duan X, li Jiang J, Xing YM, Zhu C, Song Q, Yu $Q R$. Antitumor and anti-inflammatory effects of oligosaccharides from Cistanche deserticola extract on spinal cord injury. Int J Biol Macromol 2019; 124: 360367.

7. Chen W, Lin $H-R$, Wei C-M, Luo X-H, Sun M-L, Yang Z$Z$, Chen $X-Y$, Wang $H-B$. Echinacoside, a phenylethanoid glycoside from Cistanche deserticola, extends lifespan of Caenorhabditis elegans and protects from Aß-induced toxicity. Biogerontology 2018; 19(1): 47-65.

8. Zhang J, Zhang Z, Xiang J, Cai M, Yu Z, Li X, Wu T, Cai $D$. Neuroprotective effects of echinacoside on regulating the stress-active p38MAPK and NF-KB p52 signals in the mice model of Parkinson's disease. Neurochem Res 2017; 42(4): 975-985.

9. Gao S, Xu T, Guo H, Deng Q, Xun C, Liang W, Sheng W. Ameliorative effects of echinacoside against spinal cord injury via inhibiting NLRP3 inflammasome signaling pathway. Life Sci 2019; 237: 116978.

10. Zhang Y, Zhang Y, Xing J, Zhang Y, Xing J, Ai T, Wen T, Guan L, Zhao J. Protection of echinacoside against acute lung injury caused by oleic acid in rats. Free Radical Res 2007; 41(7): 798-805.

11. Council NR: Guide for the care and use of laboratory animals: National Academies Press; 2010.

12. Kojima M, Gimenes-Junior JA, Chan TW, Eliceiri BP, Baird A, Costantini TW, Coimbra R. Exosomes in postshock mesenteric lymph are key mediators of acute lung injury triggering the macrophage activation via Toll-like receptor 4. The FASEB Journal 2018; 32(1): 97-110.

13. Jiang L, Zhang L, Kang K, Fei D, Gong R, Cao Y, Pan S, Zhao M, Zhao M. Resveratrol ameliorates LPS-induced acute lung injury via NLRP3 inflammasome modulation. Biomed Pharmacother 2016; 84: 130-138.

14. Huang $X$, Xiu $H$, Zhang $S$, Zhang $G$. The role of macrophages in the pathogenesis of ALI/ARDS. Mediat Inflamm 2018.

15. Everhart MB, Han $W$, Sherrill TP, Arutiunov $M$, Polosukhin VV, Burke JR, Sadikot RT, Christman JW, Yull FE, Blackwell TS. Duration and intensity of NF-KB activity determine the severity of endotoxin-induced acute lung injury. J Immunol 2006; 176(8): 4995-5005.

16. Liu Z, Zhao H, Liu W, Li T, Wang Y, Zhao M. NLRP3 inflammasome activation is essential for paraquatinduced acute lung injury. Inflammation 2015; 38(1): 433-444.

17. You Q, Wang J, Jiang L, Chang Y, Li W. Aqueous extract of Aconitum carmichaelii Debeaux attenuates sepsisinduced acute lung injury via regulation of TLR4/NF-KB pathway. Trop J Pharm Res 2020; 19(3): 533-539.

18. Zhang Y, Li X, Grailer JJ, Wang N, Wang M, Yao J, Zhong $R$, Gao GF, Ward PA, Tan DX. Melatonin alleviates acute lung injury through inhibiting the NLRP3 inflammasome. J Pineal Res 2016; 60(4): 405-414. 